\title{
The Role of Accent and Ethnicity in the Professional and Academic Context
}

\author{
Zainab Thamer Ahmed \\ Faculty of Modern Languages and Communication, Universiti Putra Malaysia \\ 43400 UPM Serdang, Selangor, Malaysia \\ Ain Nadzimah Abdullah (Corresponding author) \\ Faculty of Modern Languages and Communication, Universiti Putra Malaysia \\ 43400 UPM Serdang, Selangor, Malaysia \\ Tel: 60389468788 E-mail: ain@fbmk.upm.edu.my \\ Chan Swee Heng \\ Faculty of Modern Languages and Communication, Universiti Putra Malaysia \\ 43400 UPM Serdang, Selangor, Malaysia \\ Tel: 60389468707 E-mail: shchan@fbmk.upm.edu.my
}

Received: 20-06-2013

doi:10.7575/aiac.ijalel.v.2n.5p.249
Accepted: 23-07-2013

Published: 01-09-2013

URL: http://dx.doi.org/10.7575/aiac.ijalel.v.2n.5p.249

\begin{abstract}
Language learning may be affected by a language instructor's accent. Many studies have been carried out to investigate whether accent has an influence on learners' perceptions toward their instructors or whether accent can affect employability. This overview links studies on accents through an empirical literature review on native and non-native accents, summarizing the most significant studies conducted to investigate learners' attitude toward accents. The learners as participants are both non-native and native speakers of a language. The results of the review demonstrated that speakers who use the standard language are preferred for prestigious jobs, whereas the nonstandard accented speakers are preferred for low-status jobs. Moreover, British and American accents are the most preferred by learners of English. Thus, the learners tended to show positive attitudes toward American and British accents and also adopt these varieties as models of pronunciation for their learning of English. In this review, limitations of some studies are highlighted and some implications for future studies related to accents, language learning at tertiary level and employability are discussed.
\end{abstract}

Keywords: Accent, Employability, Familiarity, Native speaker, Non-native speaker, Preference

\section{Background of the study}

Numerous studies have been carried out to examine whether English accents have an influence on listeners' perceptions toward speakers or not. The following section presents the most significant studies that were conducted in the field.

\subsection{Attitude towards language and accent}

Language attitude studies have a very rich history that extends across numerous decades and social scientific disciplines and have substantially contributed to the development of the field of sociolinguistics (Ryan \& Giles, 1982). Language attitude studies showed that language is a powerful social force that does more than convey intended referential information (Cargile, 2000). In other words, listeners tend to respond to linguistic and paralinguistic variation in messages as though they indicated personal and social characteristics of the speaker (Cargile \& Giles, 1998). Cargile (2000) explained this by saying that "an American may think that a stranger is "cultured" and "refined" simply because his or her accent is recognized as British" (p.165). Cargile also suggested that "such beliefs about language use can bias social interaction and often in that context where significant social decision-making is required, language attitudes represent significant communicative phenomena to investigate" (p.165).

Basically, language attitude studies focus on the social consequences of numerous language behaviors. For instance, scholars have mapped both the behavioral and the evaluative reactions of listeners to variations in speech style, speech rate, gender linked language, voice type, and code-switching, to name just a few variables (Cargile, 2000). The most studied of all language behaviors is accent as it is likely considered the most socially significant (Cargile,2000). Therefore, many studies were conducted to find out whether accent has an influence on listeners' attitudes toward speakers or not. Interestingly, the results of these studies confirmed that accents do have a great impact on listeners' attitudes or perceptions toward speakers (Brennan \& Brennan, 1981; Cheyne 1970; Gallois, Callan \& Johnstone, 1984; Giles \& Sassoon, 1983; Hogg, Joyce \& Abrams, 1984; Luhman, 1990; Strongman \& Woolsey, 1967; Wilson \& Bayard, 1992; Ytsma, 1990).

Accent can be defined as a certain form of language spoken by a subgroup of speakers of that language which is defined 
by phonological features (Holmes, 1992). Moreover, Lippi-Green (1997) defined accent as "a loose bundles of prosodic and segmental features distributed over geographic and/or social space" (p.42). The terms 'accent' and 'dialect' often overlap and are used interchangeably. Thus, Hughes and Trudgill (2003) distinguished the terms 'dialect' and 'accent' from each other by saying that "dialect refers to varieties distinguished from each other by differences of grammar and vocabulary", while "accent refers only to varieties of pronunciation" (p.3). According to Ryan and Bulik (1982) variations in the accent with which a language is spoken tend to be viewed primarily as regional (for example, Southern American versus Northern American), social class (for example, upper versus middle versus working class), or ethnic (for example, Black English or Spanish accented English versus standard American) (p.51).

\subsection{Standard versus non-standard accents}

Previous language attitude studies concentrated on listeners' attitudes toward different accents. It is generally believed that the level of prestige accorded to language varieties is heavily influenced by two important factors, that of social structure and cultural value systems (Ryan \& Giles, 1982). Thus, many language attitude studies were conducted to confirm this particular perspective. For instance, Wilson and Bayard (1992) compared New Zealand listeners' judgments of New Zealand, Canadian, Australian, and British accented English (Cargile \& Giles, 1998). Also, Paltridge and Giles (1984) investigated reactions toward speakers of many different French-accented varieties (Cargile \& Giles, 1998). These studies and many other similar ones have found almost the same results. The results have indicated that most accents can be classified by the degree to which they are considered "standard" or "non-standard" within a particular community. Moreover, the results have showed that, usually the standard variety is more often associated with speakers from a high socioeconomic status group whereas the non-standard varieties are usually associated with lower classes (Cargile \& Giles, 1998). Ryan and Bulik (1982) conducted a study to investigate Anglo-American judgments toward standard and nonstandard German and American accented English. The results indicated that nonstandard accents had a negative impact on participants' ratings on all measures, but social class in particular, had an impact on status trait and speech intelligibility. Generally, the standard accent was judged more favorably.

Another study conducted in the United States showed that native speakers' evaluations of whether varieties of English speech are considered standard or non-standard are based mainly on regional lines. Lippi-Green (1997) explained that Southern United States English and New York English were obviously varieties being discriminated and were always evaluated less favorably in terms of correctness. Milroy's (2001) analysis revealed that the negative ratings of Southern US speech are linked to rural poverty and a poor standard of education. Additionally, Fought (2002) stated that perceptions towards varieties of Southern US English were possibly unjustifiably prejudiced by links to AfricanAmerican Vernacular English (AAVE).

Research indicated that the standard variety of accent is often associated with a high socioeconomic status group whereas the nonstandard varieties are usually associated with the lower class. Hence, Fishman (1971) distinguished between standard and nonstandard accent by saying that "a standard variety is that most often associated with status, the media, and power, whereas a nonstandard variety is one that is often associated with a lower level of socioeconomic success" (p.25).

Similarly, Bex and Watts (1999) defined the standard variety as "the variety of a language based on the speech and writing of educated speakers and which has the highest degree of respect in a particular speech community" (p.7). Furthermore, Richards, Platt and Platt (1992) defined the non-standard variety as "a spoken or written variety which is not accorded the highest prestige and which differs in terms of pronunciation, grammar or vocabulary from the standard" (p.248).

\section{Sources of data}

The search for language attitude empirically-based papers was carried out in three stages. Firstly, a general web-based search was conducted using keywords, such as accent, standard, nonstandard, employability, ethnicity, employment interview, perceptions, and attitudes. Secondly, related full papers were then downloaded and indexed. Where only abstracts of papers were found, the title of the paper, authors' names, journal name, and other details were noted down to be further pursued. Thirdly, searches were made from institutionally subscribed online databases in order to locate papers and theses related to research on accent. The online databases which included Scopus and ISI indexed journals. The searches yielded a total of 78 papers. However, the review was further narrowed down to two chosen areas that were relevant to the investigation of accent, English language learning at the tertiary level and employability. As a result of this focus, only 45 papers were selected for review. The excluded papers concentrated more on linguistic investigation, such as accent in the context of phonetics and phonology. Rather, this review concentrates on studies on accent as a sociolinguistic phenomenon.

\section{Method}

The present review follows the guidelines forwarded by Creswell (1994), which explained that the target of a review is to sum up the accumulated state of knowledge regarding the area of interest and to highlight significant problems that in previous studies have remained unsolved (Sim \& Hew, 2010). This is achieved by comparing the results of the previous studies, summarizing the previous studies in relation to perceptions toward native and non-native accents, critically examining the methodologies that were employed in the studies by looking at negative and positive aspects of what the researchers have done in their studies, and making suggestions for future studies regarding perceptions to accents. The present overview adopted the constant-comparative method that was created by Lincoln and Guba (1985). This particular method includes investigation of each individual paper, identifying numerous themes, comparing themes, and attaining theme saturation. 


\section{Findings from related studies}

This section provides the results of related studies with regard to accent, ethnicity, and employability. This section also provides the results with regard to the link between accent familiarity and preference.

\subsection{Accent, employability and English language learning at tertiary level}

Many studies in the field of language attitudes have indicated that a speaker's accent can influence his or her chances of success in an employment interview. In other words, accent can play an important role in the perceptions and attitudes of a person's characteristics. Generally, the results of the studies that were conducted have indicated that standard accented speakers are favored for prestigious jobs, whereas the nonstandard accented speakers are favored for less desirable jobs (Cargile, 2000).

For instance, one of the earliest studies conducted to examine the impact of accent in an employment interview context involved forty employment interviewers who were asked to listen to speech by African-American and Anglo-American speakers with accented English, and to evaluate their employability for five different jobs. Great differences were found only for the highest status jobs in which a standard-American English speaker was evaluated as being more employable than speakers of African-American Vernacular English (AAVE) and Southern White English dialect (Hopper \& Williams, 1973). Other studies that were conducted in 1977 to investigate the same issue reached the same conclusion which demonstrated that employment interviewers preferred hiring standard American English accented speakers for high status jobs over non-standard AAVE speakers (Hopper, 1977; Rey, 1977).

Along the same lines, two experiments were conducted to investigate the perceptions of small businessmen and shoppers to the employment suitability of people with various Australian accents that included Anglo (Standard and Broad), Asian-Australian, and German-Australian. The matched-guise technique was adopted as an instrument to record the four varieties of accents in both experiments. The matched-guise technique involves playing a recording of the same speaker who imitates a variety of different accents, and responses were made about the accents as a form of measure that indicates attitude towards language, accent, and dialect (Solís Obiols, 2002). In the first experiment, the small businessmen were asked to imagine that they were personnel acting as employers for a large company in charge of a training program for accountants and store men. Then, they were asked to listen to the recordings of the four accents and complete a questionnaire in order to evaluate the speakers' employability based on their accents. The results showed that both the Broad Anglo and German-Australian accents were evaluated to be significantly more suitable for the training program for store men rather than for accountants. Moreover, the results showed that Standard Anglo and Asian-Australian accents were evaluated equally suitable for store men and accountant training programs. However, in the second experiment which asked European shoppers to evaluate Standard, Broad Anglo-Australian, and AsianAustralian accents using the same questionnaire, the results showed that the shoppers were able to distinguish Anglo accents of the more prestigious variety, which is the Standard Anglo Australian, as being not suitable for the position of store men in the training program.

Also, the participants evaluated the Asian accent together with the Broad Anglo accent as being less suitable than the Standard Anglo accent for the accountant training program. Overall, results of this study confirmed that listeners preferred the prestigious accents for high-status jobs and the less prestigious accents for low-status jobs (Seggie, Smith \& Hodgins, 1986).

In another study, two experiments were conducted to examine whether accent alone would be enough for discrimination in the context of an employment interview. Regional accents were chosen versus Standard German accent as the regional accent makes it possible to create a more distinguished representation of one linguistic in-group (for example, German). In the first experiment, university students were asked to listen to the recording of six speakers, four male speakers who spoke in Standard German, Berlin, Saxon, and Bavarian and two female speakers who spoke in Standard German and Saxon accents. After listening, the participants were asked to identify if the voice belonged to the same person or to a different one. Then they were told that they would hear part of a job interview and imagine that they were the manager and had to evaluate the speakers' employment suitability based on what they heard during the job interview. The results of the first experiment indicated that speakers with a Standard German accent were evaluated as being more competent than those with regional accents, and Standard German speakers were evaluated as being more employable than regional accented speakers. In addition, Standard German speakers were evaluated as having a higher socio-intellectual status compared to regional accented speakers. Among the regional accented speakers, there were significant differences indicating that Bavarian accented speakers were evaluated as having a similarly high sociointellectual status as those speaking with a standard accent, such as Berlin and Saxon accents. In the second experiment, university students, workers from different occupations, and retired people were asked to listen to the recordings of six speakers, two male speakers who spoke in Berlin and Saxon accents, and four female speakers who spoke in Berlin, Saxon, Bavarian, and Cologne accents. After that, the same procedure was carried out in the second experiment. The results of the second experiment indicated that speakers with Standard German accent were evaluated as more competent than regional accented speakers, and Standard German speakers were evaluated as more employable than those with regional accents (Rakic, Steffens \& Mummendey, 2011).

Another study found that some accents such as the German accent tend to be chosen as showing a relatively high status which might be favored over a standard accent though both are said to have a favorable upper middle class description. Specifically, Kalin, Rayko and Love (1980) examined job suitability evaluations and accentedness. Their results indicated that Canadian listeners preferred German-accented speakers for high status jobs compared to those with West 
Indies and South Asian accents, although British speakers were predictably more preferred to German-accented English speakers (Ryan \& Bulik, 1982).

Language attitude studies also demonstrated that foreign accented applicants, compared to local accented applicants, were rated less suitable for higher-status jobs, and were said to be more suitable for the lower-status jobs. Particularly, Kalin and Rayko (1978) found that foreign accented job applicants were rated lower for higher-status positions, and higher for lower-status positions (Ryan \& Giles, 1982). A similar study was conducted by Kalin and Rayko (1980) to investigate listeners' attitudes toward foreign and local accented job applicants. University students were chosen as participants and were asked to act the role of personnel consultants of a large manufacturing enterprise. The listeners who participated in the study were asked to predict how well each of the ten job applicants would do in each of four jobs of different status -- foreman, industrial mechanic, production assembler and plant cleaner. Little information on each applicant was given in the 30 -second recording of their speech, purportedly from a job interview. Five candidates spoke English with a Canadian accent and another five speakers who were foreign-born spoke fluent English with Italian, Greek, Portuguese, West African, and Slovak accents. When listeners were asked to evaluate each speaker's suitability for each of the four jobs, the listeners evaluated the English Canadian accented applicant more favorably (Ryan \& Giles, 1982).

Eisenstein (1983) claimed that non-native speakers seemed to be rated lowly by natives not only in simulated experiments. It appears to happen in real-world situations, ranging from the classroom to the workplace. Another study suggested that San Antonio area employers made the same evaluations of Spanish-accented speakers. StandardAmerican English accented speakers were preferred for hiring in a supervisory position, whereas Spanish-accented speakers were preferred for a semi-skilled position (De La Zerda \& Hopper, 1979).

In addition, two studies were conducted by Cargile (1997) to investigate the attitudes of Anglo and Asian Americans to Mandarin Chinese-accented and Standard American accented speakers in two different contexts: in an employment interview and for hiring college instructors. The researcher employed the matched-guise technique to record the voice of a male native Chinese speaker who could successfully speak English with both Chinese and Standard American accents. The results of the first study suggested that the Chinese-accented speaker was evaluated to be as equally attractive, dynamic, and possessing a similar status as the standard American speaker. Moreover, the results showed that there was no significant correlation between listener's accent, and the speaker's ethnicity as thus the variables did not influence judgments of the speaker's suitability for entry into any of four jobs of different status. In comparison with Anglo American listeners, Asian American listeners reported lower evaluations for speaker's attractiveness, but not for status and dynamism. In addition, the Chinese-accented speaker was evaluated as similar to the Standard Americanaccented speaker in being suitable for the jobs of different status. The second study found that in the classroom situation, the speaker was evaluated to be less dynamic and to possess a lower status than in the job interview situation in the first study. Also, the participants showed that the Chinese-accented speaker was evaluated as being more attractive in the interview, but he was judged to be less attractive for the classroom situation than the Standard American accented speaker.

On the other hand, attitudes of non-Asian Americans toward Chinese speakers in the context of an employment interview were investigated by using the matched-guise technique that recorded the voice of a speaker who spoke English with two target accents: standard American English and Mandarin Chinese-accented English. Before the study was carried out, an audiotape was presented to a sample of seventy-one college undergraduates in order to ensure that the target accent recordings were perceived to be an authentic representation of both accents (Cargile, 2000). Respondents listened to the audiotapes, after which they judged the quality of the speaker's accents and indicated their responses about the speaker's background. Findings revealed that individuals with nonstandard accents are evaluated to be less suitable for high-status jobs. Another study was carried out to find out if there are contradictions to the findings of the earlier research can be confirmed. One hundred and ninety two non Asian American undergraduates participated in this study. They were asked to listen to the applicant's interview and then they were told to evaluate the applicant's employment suitability. The results indicated that speakers of Mandarin Chinese-accented English were not evaluated to be either less suitable for high-status job or more suitable for low-status job. Thus, the results in this particular study were not consistent with the previous language attitude study (Cargile, 2000).

Previous language attitude studies have proved that not only speaker's accent but speaker's ethnicity can be a significant indicator for job employability in an interview. For instance, Purkiss, Perrewe, Gillespie, Mayes and Ferris (2006) investigated two ethnic signals, accent and name, as a source of discrimination that may elicit prejudicial perceptions and biased decisions. The researchers asked a non-Hispanic white male student to play different roles by speaking Standard American-English, and with Hispanic accents and having different names in the employment interview. First, the speaker posed as a potential candidate with a Hispanic accent with a Hispanic name. Then he alternated to having a Hispanic accent with a non-Hispanic name. This was followed by speaking with a Standard American-English accent and giving a Hispanic name. Finally the procedure was repeated with the speaker using a Standard American-English accent but with a non-Hispanic name. Two hundred university students who participated in this study were asked to listen and rate the recording of the different accents spoken by speakers with different names. The results indicated that the most negative evaluations were given to the job applicant who spoke with an ethnic accent and had a name that indicated his ethnicity. On the other hand, the most positive evaluation was given to the applicant who had an ethnic name but used Standard English. This reveals that ethnicity and accent affected the decision to hire. , In another study, the effects on employment decisions based on an interviewee's speech characteristics in an 
employment interview were investigated (Hopper, 1977). A significant main effect was found for ethnicity and accent. The study showed a significant interaction effect indicating that the standard-accented black applicant was evaluated as being the most likely to be employed while the white applicant who spoke non-standard accent was evaluated as least likely to be employed (Hopper, 1977).Thus, accent modification tends to have a significant effect on employability. In addition, another study investigated whether ethnicity, perceived accent or dialect, and speech comprehensibility influenced applicant employability. The results showed that there was significant difference when ethnicity and accent were taken into consideration for employability. Significant differences were found in the Spanish, Asian, African American ethnic groups in the U.S for employability. In particular, the Spanish ethnic group in the United States was evaluated more positively than the Asian and the African American group (Carlson \& McHenry 2006). On the other hand, the study found that there was no significant difference among Spanish, Asian, African American ethnic groups for employability when the perceived accent or dialect condition was minimally considered (Carlson \& McHenry, 2006).

Another study examined the effects of ethnicity and accent with job status as an added variable in the selection interview of applicants from four ethnic groups in New Zealand: the Maori, Chinese, Dutch, and white New Zealander. A significant main effect was found or ethnicity and job status in selection decision just as the researchers had expected. However, contrary to what was expected, the main effect of accent was not found to be significant. Although, the participants considered accent to be significant in their judgment, ethnicity was not considered to have influenced their judgment (Singer \& Eder, 1989). Hopper and Williams (1973) in an earlier study found that employers tended to take into consideration other factors such as intelligence and competence rather than just ethnicity to be important for employment decisions.

Most of the studies reported above used university students as participants instead of real employment interviewers (for example, Cargile, 2000; Cargile, 1997; Purkiss et al., 2006; Rakic, Steffens \& Mummendey, 2011; Singer \& Eeder, 1989). It was hat this method was a problem when researchers asked university students to imagine that they were job employers who needed to evaluate the job applicants. The university students did not have enough experience and they were not trained as to how to evaluate job applicants to make employment decisions. Thus, the students' evaluations should not be considered as real employment decisions, and if future studies were to achieve more accurate and reliable results, the researchers should use real employment interviewers reflective of expert samples for their studies.

On the other hand, Kalin and Rayko (1980) justified their choice of university students by saying that they represented the culture of the community because of their cleverness, educational achievements, and relatively high social status. Therefore, they are less likely to show prejudice in their evaluation (Ryan \& Giles, 1982). Similarly, Purkiss et al. (2006) defended their use of university students as sample interviewers, saying that "university students like managers were exposed to the similar ethnic stereotypes throughout the media and society in general" (p.163).

\subsection{Native and non-native students' attitude towards accented English}

Standard and non-standard accents can be rated differently based also on different traits such as solidarity or social attractiveness (for example, being warm, friendly, trustworthy and hardworking), status or competence (for example, intelligent, educated, successful, and competent).

Numerous language attitude studies have been conducted to investigate native and non-native listeners' attitudes toward standard and non-standard speakers of English in relation to the different traits mentioned. Generally, the results indicated that the listeners rated the standard accents more favorably with regard to status, while the non-standard accents are rated more favorably in relation to solidarity (Hirage, 2005; McKenzie, 2010, 2008; Paltrige \& Giles, 1984; Ryan, Hewstone \& Giles, 1984; Wilson \& Bayard, 1992).

Ryan et al. (1984) found that the speakers who speak with a standard accent were evaluated highly on traits related to competence, intelligence, and social status, whereas the speakers who speak with a non-standard accent were evaluated less favorably on these same traits, even by informants who themselves speak with a non-standard accent. Nevertheless, the informants who speak English with a non-standard accent evaluated the non-standard speakers more positively than standard speakers based on the solidarity trait.

Through the employment of the matched-guise technique, a study investigated Australian and American university students' attitudes toward Australian speakers who produced speech examples which were breathy, creaky, nasal, tense, and in whispery voices. The results showed that no nationality difference between Australian and American students was found. In terms of status, the male speaker with a tense voice was judged more positively than all other male voices, and significantly more positively than females with a tense voice. However, a male nasal voice was judged less positively among five male voice types, and it ranked as being less significant compared to having a tense voice. In terms of solidarity, a female breathy voice was judged more positively than the other female traits and was significantly positively ranked compared to a male breathy voice. The males with a creaky and tense voice were judged significantly more positive than the female equivalents. A nasal voice which was linked to the non-standard Broad Australian speech variety was evaluated as high on solidarity but low on status (Pittam, 1987).

Hiraga (2005) investigated 32 British university students' attitude toward six varieties of English in the U.S and Britain including that of Received Pronunciation (RP), Network American, Birmingham, New York City, West Yorkshire, and Alabama. The researcher did not employ the matched-guise technique. The researcher instead asked the informants to listen to chosen speech samples and evaluate the samples on a seven-point scale. ANOVA and the Tukey results 
conducted on the scores indicated that RP was rated the highest in terms of status, followed by Network American, New York City, Alabama, West Yorkshire, with Birmingham dialect as the lowest. In terms of solidarity, Yorkshire dialect was evaluated the highest, followed by Network American, Alabama, RP, Birmingham, and the dialect spoken in New York City was evaluated the lowest. Network American achieved a consistently high ranking (the second) in terms of status and solidarity, while RP did not achieve as high a score. The informants also evaluated the regional varieties of American English differently from the Network American variety. They evaluated urban varieties of American English in the same way they did for urban British varieties; the British informants were able to distinguish each variety of American English. Based on the results, the researcher divided the six varieties into three distinct groups (standard spoken varieties of English, dialects spoken in the rural areas, and dialects spoken in urban areas).

Similarly, another study investigated the attitudes of Hong Kong university students towards eight varieties of English which include Received Pronunciation, Tyneside English, General American English, Australian English, Philippine English, Mandarin-accented English, and two local varieties of English, one with a broad accent and the other with an educated accent. The researcher employed the verbal-guise technique in order to record the eight varieties of English. The results indicated that the standard varieties of English particularly from the 'inner circle' that include Received Pronunciation, General American English, and Australian English were evaluated more favorably than either of the local varieties in Hong Kong based on status and solidarity. On the other hand, the educated Hong Kong accent was evaluated less favorably based on status and solidarity, while the broad Hong Kong accent was always at the bottom with reference to the two traits. The results also showed that Hong Kong listeners were able to distinguish Philippine accented English, though they were not familiar with Tyneside English which is used in North-East England. However both accents were evaluated more positively than broad Hong Kong accent based on the solidarity trait. Mandarinaccented English was ranked in middle position, which more or less was equivalent to the educated Hong Kong accent (Zhang, 2009).

In addition, McKenzie (2010) investigated the attitudes of 558 Japanese undergraduate and post-graduate students towards six native and non-native varieties of English accents that included two British accents (Glasgow vernacular speech and Glasgow Standard English), two American accents (Southern US English Alabama, and Midwest US English), and two Japanese accents (moderate and heavy). The researcher employed the verbal-guise technique as an instrument because he could not find one single speaker who could persuasively produce all six varieties of English accents chosen for the purpose of his study. The results indicated that Japanese university students evaluated the native accents more favorable than Japanese English accents in terms of competence. On the other hand, the results indicated the non-native Japanese accents were evaluated more favorable in terms of solidarity.

English language learners seem to choose a particular variety of English accent when it comes to deciding the model for learning English. Language attitude studies demonstrated that students definitely responded to what they perceived to be ideal or non-ideal accents among their teachers and lecturers (Butler, 2003). For instance, Gill (1994) found that American college students evaluated the teacher who speaks English with a Malay accent less favorably than American and British teachers who speak English with American and British accents. Moreover, English language learners or students frequently view the native varieties of English accents such as British or American as the ideal accent. Thus, they tend to adopt them as a model of pronunciation for their learning (Butler, 2003). Generally, previous studies had confirmed that British and American accents are the most preferred by the students and they also tended to show positive attitudes toward them. For instance, Matsuura, Chiba, and Yamamoto (1994) conducted a study to examine Japanese college student's attitudes toward six Asian accents of English and also toward an American accent. The results indicated that the subjects' viewed American English more positively than they viewed other varieties. The subjects' reactions to the spoken accents did not correlate with their overall English proficiency at a significant level; the stronger the subjects' preference for native English, the more positive was also their attitude toward the American accent. They were also more negative toward the non-native varieties. Also, their results indicated that subjects who had a stronger instrumental motivation in learning English did not tend to show greater difference in preference between the native accent and the non-native accent, in particular, subjects who wanted to learn English because it is required for graduation. In addition, subjects who believed that the native language should be most respected in a country tended to accept the non-native accents as well as the native accent readily.

Chiba, Matsuura, and Yamamoto (1995) extended on the study conducted by Matsuura et al. (1994) to investigate Japanese university students' attitudes toward native and non-native English accents. The study addressed three hypotheses which are: 1) the respondents' familiarity with accents will influence their acceptance of different English accents, 2) respondents will judge an accent more positively when they can recognize what nationality a speaker of that particular accent is, 3) respondents with high instrumental motivation will be more positive toward the non-native English accents than those with lower instrumental motivation. The results of the study indicated that Japanese students showed preference for the American accent and responded more positively to the native English accents than to the nonnative accents because they were able to recognize the American accent easily after listening to the speech recordings of the speakers. The results of this particular study supported all the hypotheses and confirmed the findings of Matsuura et al. (1994) study.

In addition, the level of respect for the indigenous language appears to influence their perceptions to non-native English accents. The respondents seem to be very tolerant in accepting the use of non-native English accents among instructors.

In another study, McKenzie (2010) found that Japanese students identified the heavily-accented Japanese English speaker most correctly, followed by the Southern United States English and Mid-West United States English. However, 
the students established considerable difficulty in correctly identifying Scottish Standard English and Glasgow Vernacular English. The researcher concluded that the Japanese students were able to identify the heavily-accented Japanese English most correctly because they were most familiar with this variety of English. Also, the Japanese students were able to identify the U.S varieties possibly because of the general prevalence of American culture in the Japanese society. Thus, they evaluated the native accents more favorably than Japanese English accents in terms of the 'competence' trait and the non-native Japanese accent was evaluated more favorably in terms of the 'solidarity' trait.

Likewise, many other studies which investigated Korean students' attitudes towards native and non-native accents showed that Korean learners of English seem to have a strong preference for the American accent (Kim 2007). Similarly to the attitude of the Japanese students from Kim's (2007) study, it showed that Korean students also preferred the American accent the most, followed by British, and Canadian. The researcher explained these results saying that "this preference of American accent was confirmed by participants' desire and interest to learn and use American English because Korea is most connected to the USA socio-economically and culturally" (p.38). Gibb (1999) had also analyzed this particular attitude by referring to Koreans' familiarity with American culture and perception of America as an economic power, with its advanced technology and facilities for education (Kim, 2007). Similarly, it was found that Korean pre-university students preferred the American accent over the British accent, and this preference was linked with the Korean students' familiarity with the American accent (Kim, 2007).

Nejjari, Gerritsen, Van Der Haagen, \& Korzilius, (2012) examined two groups of people with reference to accent preference. The first group was familiar with Dutch-accented English while the second group was not familiar with it. The two groups included 72 British who were living in London, and 72 British who had been living in the Netherlands for ten years or more.

As such, this group of people was familiar with Dutch-accented English. The researchers recorded the accents of speakers who could speak Standard British English (BrE), a slight Dutch English accent, and a moderate Dutch English accent. They asked the participants to listen and then rate the three varieties which were recorded. The results of the study indicated that BrE had more status than the slightly Dutch accented English and the moderately Dutch accented English. In terms of affect, British English and slightly accented Dutch English were more appealing than moderately Dutch accented English. In terms of intelligibility, the British English speakers were rated as the most intelligible speakers, followed by the moderately Dutch accented speakers and slightly Dutch accented speakers. In terms of speech comprehensibility, the British English speakers were found to be most comprehensible followed by the slightly accented speakers and the moderately accented speakers. However, no significant differences were found in the interpretability of the three accents. In terms of the relationship between attitude, intelligibility, speech comprehensibility, and interpretability, there was a significant positive correlation between status and affect, status and intelligibility, status and speech comprehensibility, affect and speech comprehensibility, intelligibility and speech comprehensibility. In terms of familiarity, listeners who are familiar with Dutch-accented English significantly evaluated the slightly accented Dutch speakers and moderately Dutch accented English speakers as having less status compared to listeners who were not familiar with Dutch accented English. They also evaluated the slightly Dutch accented English speakers and moderately Dutch accented English as being more intelligible compared to listeners who were not familiar with Dutch-accented English. In addition, the two groups of listeners were able to correctly interpret the intentions of the speaker in all situations. Additionally, Bernaisch (2012) investigated 169 Sri Lankan informants' attitudes towards American English, British English, Sri Lankan English, and Indian English. The researcher adopted a likert scale questionnaire and the results showed that speakers of Sri Lankan English evaluated British English most positively. However, other varieties (e.g. Sri Lankan, American, and Indian English) were also evaluated positively by the informants. Factors such as age, gender, ethnicity, occupation, place of residence, language acquired first, proficiency in English, and staying abroad did not appear to have any influence on the rating of British English. Based on the findings, it could be concluded that subjects' familiarity with a particular accent could influence their perception about a particular accent. Dalton-Puffer, Kaltenboeck and Smit (1997) studied Austrian university student's attitudes toward native and non-native accents. The results showed that Austrian university students were able to identify all the varieties of native and non-native accents correctly after listening to the speech recordings of the different speakers. The participants also preferred Received Pronunciation the most. The results also demonstrated that the students preferred general American accent, followed by near RP accent. However, the Austrian students evaluated the two Austrian varieties of English accents negatively.

On the whole, non-native English learners tend to prefer either British or American accent more than their own local accents.

In another study, Matsuura, Chiba, and Fujieda (1999) examined Japanese university students' perception of intelligibility and speech comprehensibility in relation to familiar and unfamiliar English accents. Participants listened to recordings of six accents. The students were then asked to listen to the recordings of the six native speakers and fill in missing words in a text. The Japanese students were asked to show their evaluations individually by using semantic differential scales in order to investigate how comprehensible the accents were. The results of the study indicated that though the students felt that a statement was easy to understand, it did not essentially mean they were able to write out the words or understand the message correctly. The period of exposure and familiarity could lead to higher perceived comprehensibility but it did not essentially lead to better understanding of the message. The students' evaluations of speech were likely influenced by other salient verbal features for instance, intonation, clarity, fluency, and pauses. It was also found that the extent to which a particular English variety was rated as understandable for a listener may differ from speaker to speaker. The researchers explained that this could be related not only to a listener's English proficiency 
Another language attitude study showed that people with different ages identify the ethnicity of speakers with different degrees of accuracy. Tan (2012) investigated if listeners were able to distinguish the ethnicity of 325 Singaporean speakers (Malay, Chinese and Indian) of English and also whether demographic differences among the listeners would influence their identification of ethnic accents. A perception test stimulus was used to elicit responses to recordings of 10 Singaporean males, three were Chinese speakers of English, three were Malay speakers of English, and four were Tamil speakers of English. This particular methodology involves informants listening to a set of test stimuli and they were then asked to identify the ethnic group of the speakers. The results indicated that the Chinese speaker was the most correctly identified. Moreover, the results indicated that listeners' age mattered in the identification of speaker ethnicity especially among Malay and Indian speakers. Accuracy was highest with the oldest group of listeners and lowest with the youngest group of listeners.

A particular accent may have an effect on students' perception of a lecturer or teachers' overall performance in the classroom. This idea was the focuses of Butler's (2003) work in which Korean elementary school students' attitudes towards teachers with an American-English accent and Korean English accent were investigated. In addition, the researcher investigated the effects of teachers' accent on students' listening comprehension. The results of the study demonstrated that the Korean elementary school students believed that the American-accented English speaker has a higher self-esteem, and the speaker concentrates more on fluency than on accuracy, had better accent, and would speak only English while explaining rather than using Korean in the English class. The students also preferred the American-accented English speaker as their English teacher. However, the listening comprehension examination showed that the students who listened to the Korean-accented English tape performed much better when the text difficulty matched their grade level. But, when the texts were either easier or more difficult for their grade level, there were no difference in their listening scores when they had teachers with different accents.

Generally, students seem to perceive the non-native varieties of English accents negatively. For instance, Shim's (2002) study showed that Korean learners did not consider Korean accented English as a good model for learning English. They termed non native accent as "bad accent" and some of them felt that they did not need to understand Indian, Singaporean, or Filipino English and the results showed that they could not distinguish these varieties (p.148). But, all the students wanted to learn English spoken with an American accent (Kim, 2007). Similarly, Australian university students displayed negative attitudes towards their own Australian accented English. They were also able identify the native and non-native varieties of English accents (Dalton-Puffer et al., 1997).

\section{Conclusion}

The review showed a preference in the literature for the matched-guise technique as a suitable methodology for obtaining responses to recorded accents. This methodology involves playing a recording of a speaker imitating a variety of different accents and listeners stating their attitudes towards those recorded accents. However, the matched guise technique has been criticized by many scholars because of several reasons. These would be that the technique could exhibit non-existent stereotypes and that responses are often constrained by the data provided. Another common criticism of the technique is that the speech recordings presuppose a singular style of an identified variety. The technique has also been criticized because the voice of the speaker could sound very unnatural since the recording is from one single speaker and reading aloud a prepared text using different accented speech varieties. Participants too would easily be able to recognize the different accents as that spoken by one person.

A modified version of the matched-guise technique called the verbal-guise technique was developed and used to overcome the disadvantages of the matched guide technique. The verbal-guise technique involves participants listening to recordings of natural speech from a number of different speakers rather than listening to only one single speaker who imitates all accents while taking on different roles such as that of lecturers and interviewers. The verbal-guise technique uses a semantic-differential scale, which meaningfully scales a number of traits according to descriptors such as fluent/not fluent, gentle/not gentle, confident/not confident, qualified/not qualified, and clear/unclear.

Choosing the setting for the sociolinguistic scene to locate the study is also important. There must be reasoned choices for the accents to be investigated. For example, British and American accents should never be left out due to their influence and globalness. Previous studies have included British and American accents or focused on the varieties of accents related to the two languages. Accent studies are peculiar to the geographical location as those revealed in Korea, Japan and Sri Lanka. Thus, it would appear that each geographical location would have peculiarities that would contribute to an understanding of accent. In Malaysia, investigating perceptions and attitudes towards accents is relevant and not in abundance. Malaysia is rich in accents by virtue of its linguistic diversities and the presence of many tertiary institutions which cater to both local and international students. In addition, theses tertiary institutions also employ faculty staffs that are local and international. The workplace is also an important research site for investigating accents. Again, the workplace can be constrained by a geographical location in which perceptions towards accents could be different.

Findings have been somewhat diverse according to geographical location. In countries such as Korea and Japan, English language learners seem to prefer the American accent but, in some other countries particularly in Malaysia, it is still unclear which accent learners of English and employers seem to prefer and consider ideal for the workplace. While the review has shown that accent studies have been quite extensive, there is still room for further studies to give insights into accent peculiarities with regard to ethnicity, familiarity, speech comprehensibility according to geographical 
location. Sociolinguistic contributions of this nature are very much about social acceptance defined by a society.

\section{References}

Bernaisch, T. (2012). Attitudes towards Englishes in Sri Lanka. World Englishes, 31 (3), 279-291.

Bex, T., \& Watts, R. J. (Eds.). (1999). Standard English: The widening debate. Routlege.

Brennan, E. M., \& Brennan, J. S. (1981). Accent scaling and language attitudes: Reactions to Mexican-American English speech. Language and Speech, 24, 207-221.

Butler, Y. G. (2003). Perception versus reality: how important is it that Korean elementary school teachers speak "Good English". World Papers in Educational Linguistics, 19, 1-25.

Cargile, A. C. (1997). Attitudes toward Chinese-accented speech: An investigation in two contexts. Language and Social Psychology, 16,434-443.

Cargile, A. C. (2000). Evaluations of employment suitability: Does accent always matter. Employment counseling, 37,165-176.

Cargile, A. C., \& Giles, H. (1998). Language attitudes toward varieties of English: An American-Japanese context. Applied Communication Research, 26, 338-356.

Carlson, H. K., \& McHenry, M. A. (2006). Effect of accent and dialect on employability. Journal of Employment Counseling, 43, 70-83.

Chiba, R., Matsuura, H., \& Yamamoto, A. (1995). Japanese attitudes toward English accents. World Englishes, 14, $77-$ 86.

Chyne, W. (1970). Stereotyped reactions to speakers with Scottish and English regional accents. British Journal of Social and Clinical Psychology, 9, 77-79.

Creswell, J. (1994). Research design qualitative and quantitative approaches. Thousand Oakes: Sage Publications.

Dalton-Puffer, C., Kaltenboeck, G., \& Smit, U. (1997). Learner attitudes and L2 pronunciation in Austria. World Englishes, 16, 115-128.

De La Zerda, N., \& Hopper, R. (1979). Employment interviewers' reactions to Mexican-American speech.

Communication Monographs, 46, 126-134.

Eisenstein, M. (1983). Native reactions to non-native speech: A review of empirical research. Studies in Second Language Acquisition, 5,160-176.

Fishman, J. A. (1971). Sociolinguistics: A brief introduction. Boston: Rowley.

Fought, C. (2002). California students' perceptions of, you know, regions and dialects?. In D. Long, \& D. Preston, D. (Eds.), A handbook of perceptual dialectology, vol.2 (pp.113-34). Amesterdam: Benjamins.

Gallois, C., Callan, V. J., \& Johnstone, M. (1984). Personality judgments of Australian Aborigine and White speakers: Ethnicity, sex and context. Journal of Language and Social Psychology, 3, 39-57.

Gibb, M. (1999). A comparative study of attitudes towards varieties of English held by professionals and tertiary level students in Korea. The Korea TESOL Journal, 2 (1), 31-42.

Giles, H., \& Sassoon, C. (1983).The effect of speaker's accent, social class background and message style on British listeners' social judgments. Language and Communication, 3, 305-313.

Gill, M. M. (1994). Accent and stereotypes: Their effect on perceptions of teachers and lecture comprehension. Applied Communication Research, 22, 349-361.

Hiraga, Y. (2005). British attitudes towards six varieties of English in the USA and Britain. World Englishes, 24,289308.

Hogg, M. A., Joyce, N., \& Abrams, D. (1984). Diglossia in Switzerland? A social identity analysis of speaker evaluation. Journal of Language and Social Psychology, 3, 185-196.

Holmes, J. (1992). An introduction to sociolinguistics. New York, NY: Longman.

Hopper, R. (1977). Language attitudes in the employment interview. Communication Monographs, 44, 346-351.

Hopper, R., \& Williams, F. (1973). Speech characterstics and employability. Speech Monographs, 44, 296-302.

Hughes, A., \& Trudgill, P. (2003). English accents and dialects ( $3^{\text {rd }}$ ed.). London, England: Arnold.

Kalin, R., Rayko, D. (1978). Discrimination in evaluative judgments against foreign-accented job candidates. Psychological Reports, 43, 1203-1209.

Kalin, R., Rayko, D. (1980).The social significance of speech in the job interview. In S. T. Clair, R. N. \& H. Giles (Eds.), The social and psychological contexts of language (pp.39-50). Hillsdale: Lawrence Erlbaum Associations.

Kalin, R., Rayko, D. S., \& Love, N. (1980).The perception and evaluation of job candidates with four ethnic accents. In H. Giles, W.P. Robinson, \& P. Smith (Eds.), Language: Social Psychological perspectives. Oxford, England: Pergamon Press. 
Kim, Y. S. (2007). Korean Attitude towards Varieties of English, MSc Thesis, University of Edinburgh.

Lincoln, Y. S., \& Guba, E.G. (1985). Naturalistic inquiry. Beverly Hills, CA: Sage Publications.

Lippi-Green, R. (1997). English with an accent: Language ideology and discrimination in the United States. Routledge. Luhman, R. (1990). Appalachian English stereotypes: Language attitudes in Kentucky. Language in Society, 19, 331348 .

Matsuura, H., Chiba, R., \& Fujieda, M. (1999). Intelligibility and comprehensibility of American and Irish Englishes in Japan. World Englishes, 18 (1), 49-62.

Matsuura, H., Chiba, R., \& Yamamoto, A. (1994). Japanese college students' attitudes towards non-native varieties of English. In D. Graddol \& J. Swann (Eds.), Evaluating language (pp.52-61). BAAL: Multilingual Matters.

McKenzie, R. M. (2008). Social factors and non-native attitudes towards varieties of spoken English: A Japanese case study. International Journal of Applied Linguistics, 18 (1), 64-88.

McKenzie, R. M. (2010). The social psychology of English as a global language: Attitudes, awareness and identity in the Japanese context. London, England: Springer.

Milroy, L. (2001). The social categories of race and class: Language ideology and sociolinguistics. In N. Coupland, S. Sarangi, \& C.N. Candlin (Eds.), Sociolinguistics and Social Theory (PP.16-39). London, England: Rutledge.

Nejjari, W., Gerritsen, M., Van Der Haagen, M., \& Korzilius, H. (2012). Responses to Dutch-accented English. World Englishes, 31 (2), 248-267.

Paltrige, J., \& Giles, H. (1984). Attitudes towards speakers of regional accents of French: Effects of regionality, age and sex of listeners. Linguistiche Berichte, 90, 71-85.

Pittam, J. (1987). Listeners' evaluations of voice quality in Australian English speakers. Language and Speech, 30 (2), 99-113.

Purkiss, S. L. S., Perrewe, P. L., Gillespie, T. L, Mayes, B. T., \& Ferris, G. R. (2006).Implicit sources of bias in employment interview judgments and decisions. Organizational Behavior and Human Decision Processes, 10, $152-167$.

Rakic, T., Steffens, M. C., \& Mummendey, A. (2011). When it matters how you pronounce it: The influence of regional accents on job interview outcome. British Journal of Psychological Society, 102, 868-883.

Rey, A. (1977). Accent and employability: Language attitudes. Language Sciences, 47, 7-12.

Richards, J., Platt, J., \& Platt, H. (1992). Longman Dictionary of Applied Linguistics (3 ${ }^{\text {rd }}$ ed.). Harlow: Longman.

Ryan, E. B., \& Bulik, C. M. (1982). Evaluations of middle class and lower class speakers of standard American and German-accented English. Language and Social Psychology, 1, 51-61.

Ryan, E. B., \& Giles, H. (1982). Attitudes towards language variation: Social and applied contexts. London, England: Edward Arnold.

Ryan, E. B., Hewstone, M., \& Giles, H. (1984). Language and intergroup attitudes. In J. Eiser (Eds.), Attitudinal judgment (pp.135-160). New York, NY: Springer.

Seggie, I., Smith, N., \& Hodgins, P. (1986). Evaluations of employment suitability based on accent alone: An Australian case study. Language Sciences, 8 (2), 129-140.

Sim, J. W. S., \& Hew, K. F. (2010). The use of weblogs in higher education settings: A review of empirical research. Educational Research Review, 5, 151-163.

Singer, M., \& Eder, G. S. (1989). Effects of ethnicity, accent, and job status on selection decisions. International Journal of Psychology, 24, 13-34.

Solís Obiols, M. (2002). The matched guise technique: A critical approximation to a classic test for formal measurement of language attitudes. Noves SL. Revista de Sociolinguistica, 1, 1-6.

Strongman, K., \& Woolsey, J. (1967). Stereotypes reactions to regional accents. British Journal of Social and Clinical Psychology, 6, 164-167.

Shim, R. J. (2002). Changing attitudes towards TEWOL in Korea. Journal of Asia Pacific Communication, 12 (1), $143-$ 158.

Tan, Y. Y. (2012). Age as a factor in ethnic accent identification in Singapore. Journal of Multilingual and Multicultural Development, 33 (6), 569-587.

Wilson, J., \& Bayard, D. (1992). Accent, gender, and the elderly listener: Evaluation of NZE and other English accents by rest home residents. Te Reo, 35, 19-56.

Ytsma, J. (1990, June). School children's language attitudes in Friesland. Paper presented at the annual meeting of the International Communication Association, Dublin, Ireland.

Zhang, Q. (2009). Hong Kong people's attitudes towards varieties of English. Newcastle Working Papers in Linguistics, $15,151-173$. 